\title{
Entonox $^{\circledR}$ inhalation to reduce pain in common diagnostic and therapeutic outpatient urological procedures: a review of the evidence
}

\author{
A Young ${ }^{1}$, M Ismail ${ }^{1}$, AG Papatsoris ${ }^{1}, \mathrm{JM}_{\text {Barua }}{ }^{2}, \mathrm{JG}_{\text {Calleary }}{ }^{3}, \mathrm{~J} \mathrm{Masood}^{1}$ \\ ${ }^{1}$ Barts and The London NHS Trust, UK \\ ${ }^{2}$ Barking, Havering and Redbridge University Hospitals NHS Trust, UK \\ ${ }^{3}$ Pennine Acute Hospitals NHS Trust, UK
}

\section{ABSTRACT}

INTRODUCTION Entonox ${ }^{\circledR}$ (50\% nitrous oxide and 50\% oxygen; BOC Healthcare, Manchester, UK) is an analgesic and anxiolytic agent that is used to successfully reduce pain and anxiety during dental, paediatric and emergency department procedures. In this article we review the application and efficacy of Entonox ${ }^{\circledR}$ in painful local anaesthesia urological procedures by performing a systematic review of the literature.

METHODS A MEDLINE ${ }^{\circledR}$ search was performed using the terms 'nitrous oxide', 'Entonox', 'prostate biopsy', 'flexible cystoscopy' and 'extracorporeal shock wave lithotripsy'. English language publications of randomised studies were identified and reviewed.

RESULTS The search yielded five randomised studies that investigated the clinical efficacy of Entonox ${ }^{\circledR}$ as an analgesic for day case urological procedures. Three randomised controlled trials (RCTs) investigated Entonox ${ }^{\circledR}$ in transrectal ultrasonography guided prostate biopsy. All three reported significant reductions in pain score in the Entonox ${ }^{\circledR}$ versus control groups. One RCT reported significant reduction in pain during male flexible cystoscopy in the Entonox ${ }^{\circledR}$ group compared with the control group. One RCT, which examined the use of Entonox ${ }^{\circledast}$ during extracorporeal shock wave lithotripsy, found its use significantly decreased the pain score compared with the control group and this was comparable to intravenous pethidine.

CONCLUSIONS Evidence from varied adult and paediatric procedures has shown Entonox ${ }^{\circledR}$ to be an effective, safe and patient acceptable form of analgesia. All published studies of its use in urological day case procedures have found it to significantly reduce procedural pain. There is huge potential to use this cheap, safe, effective analgesic in our current practice.

\section{KEYWORDS}

Urology - Analgesia - Pain

Accepted 6 August 2011

\section{CORRESPONDENCE TO}

Junaid Masood, 3 Taleworth Close, Ashtead, Surrey KT21 2PU, UK

T: +44 (0)7815 183 605; E: junaido@aol.com

\begin{abstract}
A large proportion of diagnostic and some therapeutic urological procedures in the UK are performed on an outpatient basis, often without sedative analgesia. Transrectal ultrasonography guided prostate biopsy and flexible cystoscopy represent the most common diagnostic urological procedures. Extracorporeal shockwave lithotripsy (ESWL) remains the only non-invasive treatment for renal tract calculi and is still used to treat the vast majority of upper urinary tract stones. While these procedures are performed successfully on an outpatient basis, there is increasing evidence that they are painful. In this article we review the English language literature for evidence of the potential role of Entonox ${ }^{\circledR}$ (50\% nitrous oxide and $50 \%$ oxygen; BOC Healthcare, Manchester, UK) as an analgesic option in these 'office' urology procedures.
\end{abstract}

\section{What is Entonox ${ }^{\circledR}$ and how does it work?}

Nitrous oxide is a colourless gas that was first discovered in 1776 by Joseph Priestley. ${ }^{1}$ Though its uses as an analgesic and sedative were reported sporadically during the following 200 years, it was not until the 1950s that it gained popularity. Langa and others first popularised its use as an anxiolytic. ${ }^{2,5}$ Nitrous oxide is highly soluble in blood: arterial concentrations reach plateau concentrations within 10 minutes of commencing inhalation. Nitrous oxide does not bind to haemoglobin, is quickly diffused via cellular membranes and is eliminated unchanged via the lungs. Commencement of analgesia may be noted from 20 seconds of inhalation with a peak effect after 3-5 minutes. All forms of sensation are affected. There is also anxiolysis, amnesia and euphoria. However, the reflexes of coughing and airway 
protection are not noticeably altered. ${ }^{4}$ The rapidity of both onset and loss of effect make it an attractive analgesic option for day case procedures.

Parbrook produced an approximate dose related response for most clinically observed characteristics of nitrous oxide, with the degree of analgesia increasing in proportion with the rising nitrous oxide concentration. ${ }^{5,6}$ Nitrous oxide effects were classified into four zones of analgesia. Early studies evaluating its potency in comparison with opioid analgesics reported that $30 \%$ nitrous oxide is equivalent to $10-15 \mathrm{mg}$ of morphine. ${ }^{7,8}$ Entonox $^{\circledR}$, a mixture of $50 \%$ nitrous oxide in oxygen, can be used in spontaneously breathing patients to provide analgesia for short duration procedures where pain is predictable.

\section{Adverse effects of Entonox ${ }^{\circledR}$}

The most common side effects of Entonox ${ }^{\circledR}$ are transient nausea and light headedness. Nitrous oxide may cause some slight cardiac depression and should be used with caution in patients with congestive cardiac failure and in those with chronic obstructive airway disease. ${ }^{9}$ Volume or pressure in air filled body cavities increases as nitrous oxide diffuses into these spaces. The administration of nitrous oxide is therefore contraindicated in the presence of head injury or elevated intracranial pressure, drug intoxication, haemodynamic instability, pneumothorax, bowel obstruction or any other condition with a pathological, air filled body cavity. ${ }^{10}$

While concerns have been raised regarding prolonged administration or exposure to nitrous oxide, Weimann reports that there is little evidence to support claims of it causing reduction in fertility or predisposing to the development of cancer. ${ }^{11}$ Chronic use of nitrous oxide has been reported to affect haematopoiesis by causing bone marrow depression and inactivate vitamin B12 in humans but short-term nitrous oxide exposure in normal persons appears to have no significant sequelae. ${ }^{12}$

\section{Evidence for Entonox ${ }^{\circledR}$ from other specialties}

Entonox ${ }^{\circledast}$ has found widespread use as an analgesic for procedural related pain in both adults and children. A French survey of Entonox ${ }^{\circledR}$ use in procedural related pain in children found it to be a useful analgesic for a variety of procedures. ${ }^{13}$ The survey reported $93 \%$ of the 647 children that were able to complete the post-procedure related questionnaire said they would accept Entonox ${ }^{\circledR}$ if a new procedure was to be performed. All side effects were transient and no serious effects were noted in the more than 1,000 children participating in the survey. Entonox ${ }^{\circledast}$ has also been shown to be a very successful and useful clinical adjunct in the management of paediatric dental patients. ${ }^{14}$

There are widespread reports of Entonox ${ }^{\circledR}$ as a successful and patient accepted analgesic during labour. ${ }^{15}$ In a National Birthday Trust survey, $90 \%$ of mothers, partners and midwives agreed that Entonox ${ }^{\circledR}$ was a good method of pain relief in labour whereas only $58 \%$ found pethidine to be useful. ${ }^{16}$

In their systematic literature review, Welchman et al found Entonox ${ }^{\circledR}$ to provide comparable analgesia to intravenous sedation in patients undergoing colonoscopy. ${ }^{17}$
They reported a more rapid psychomotor recovery with Entonox ${ }^{\circledR}$. This was supported by the randomised controlled trial (RCT) of Forbes and Collins, who found recovery after colonoscopy to be significantly quicker in patients given Entonox ${ }^{\circledR}$ alone compared with standard intravenous sedation..$^{18}$ Maslekar et al found that in patients undergoing colonoscopy, those receiving Entonox ${ }^{\circledR}$ had a shorter time to discharge and reported significantly less pain and higher patient satisfaction than those who received intravenous sedation. ${ }^{19}$ Entonox ${ }^{\circledR}$ use in this setting facilitates earlier patient discharge and has the potential to reduce the costs of periprocedural nursing.

There have also been reports of successful use of Entonox $^{\circledR}$ in preventing pain in renal percutaneous biop$\operatorname{sies}^{20}$ and in the management of refractory pain in the terminally ill. ${ }^{21}$

\section{Day case urological procedures are painful}

A significant number of urological patients undergo transrectal ultrasonography guided biopsy, flexible cystoscopy and ESWL. The vast majority of these procedures in the UK are performed on an outpatient basis without sedative analgesia. The demand for these diagnostic (prostate biopsy, flexible cystoscopy) and therapeutic (ESWL) procedures is likely to continue to increase.

Performing these procedures on an outpatient basis has significant implications on financial and workforce resources. However, the procedures must be tolerable to the patients who undergo them. Up to a quarter of patients undergoing prostatic biopsy find it moderately to extremely painful ${ }^{22}$ and $19 \%$ would refuse to have the procedure without analgesia. ${ }^{25} \mathrm{ESWL}$ is the first line intervention for most urinary tract calculi but it is tolerated poorly without analgesia. The lithotripter, stone location, age, sex and amount of energy used have all been shown to determine the analgesic requirements of ESWL. ${ }^{24}$ Poor patient analgesia results in poor compliance. This can make stone targeting more challenging. Flexible cystoscopy, especially in younger men, is a painful procedure even with periurethral lubrication. ${ }^{25}$

Despite current analgesic options, there is a demand for an agent that would improve patient tolerance of these procedures while allowing it to be performed on an outpatient basis. The ideal agent would have rapid onset, be quickly reversible, provide predictable pain relief (with minimal side effects and no adverse effects) and be patient acceptable. Ideally, this agent would be cost comparable with the analgesia used currently.

\section{Methods}

A MEDLINE ${ }^{\circledR}$ search was performed using the terms 'nitrous oxide' and in turn each of 'prostate biopsy', 'flexible cystoscopy' and 'extracorporeal shock wave lithotripsy'. This was repeated using the term 'Entonox' in place of 'nitrous oxide'. This identified 39 papers. From this group only those published in English were included and all duplicates were excluded. The abstracts for the remaining papers were reviewed and any that were not related to the urological procedures used as search terms (prostate biopsy, flex- 
ible cystoscopy, ESWL) were excluded, as were all papers that were not randomised studies. Five abstracts appeared relevant and the full papers were reviewed.

\section{Results}

Our MEDLINE ${ }^{\circledR}$ search identified five randomised trials that investigated the clinical efficacy of Entonox ${ }^{\circledR}$ as an analgesic for day case urological procedures that were published in the English language. Three RCTs investigated Entonox ${ }^{\circledR}$ in transrectal ultrasonography guided prostate biopsy. All three reported significant reductions in pain score in the Entonox $^{\circledR}$ versus control groups. Masood et al randomised 110 patients to receive Entonox ${ }^{\circledR}$, air or a placebo. ${ }^{9}$ They noted a significant decrease in pain in the Entonox ${ }^{\circledR}$ versus air and Entonox ${ }^{\circledR}$ versus placebo groups $(p<0.001)$. The vast majority of patients $(96 \%, 49$ of 51$)$ in the Entonox ${ }^{\circledR}$ group would undergo the procedure again if required, with only 2 of 51 requesting additional analgesia for any future procedure. In contrast, $47 \%$ of patients (21 of 45$)$ in the air group would request additional analgesia to undergo future biopsies. All patients in this study received $10 \mathrm{ml}$ of $2 \%$ lidocaine per rectum before the procedure.

Masood et al's findings are supported by the RCT of McIntyre et al where 50 patients were randomised to breathe Entonox $^{\circledR}$ or room air prior to and during prostate biopsies. ${ }^{26}$ The visual analogue pain scores were significantly lower in the Entonox ${ }^{\circledR}$ compared with the air group $(p<0.001)$. The mean pain score in the air group was $34(100 \mathrm{~mm}$ visual analogue scale), which supports the belief that prostate biopsy is moderately painful without analgesia.

When Manikandan et al compared Entonox ${ }^{\circledR}$ with periprostatic lidocaine nerve block during prostate biopsy in their prospective RCT of 235 patients, they found both analgesic options significantly reduced procedural pain $\left(p<0.01\right.$ lidocaine; $p=0.028$ Entonox $\left.^{\circledR}\right)$ compared with the control group. ${ }^{27}$ They reported no significant difference in pain scores between the Entonox ${ }^{\circledR}$ and lidocaine groups. However, one important advantage of using Entonox ${ }^{\circledR}$ over periprostatic block during prostate biopsies is that it reduces anal sphincter tone due to its muscle relaxant properties and hence reduces pain as a result of rectal probe insertion.

Another RCT reported significant reduction in pain during male flexible cystoscopy in the Entonox ${ }^{\circledR}$ group compared with the control group. ${ }^{25}$ Calleary et al performed a prospective RCT of 61 male patients under the age of 55 undergoing flexible cystoscopy. All patients received $20 \mathrm{ml} 2 \%$ lidocaine gel per urethra 15 minutes prior to the procedure. The groups were matched equally in terms of age, indication for cystoscopy and diagnosis. However, the Entonox ${ }^{\circledR}$ group had significantly decreased visual analogue and verbal scores for pain during cystoscopy $(p<0.001)$. Side effects occurred more frequently in the Entonox ${ }^{\circledR}$ group $(p<0.05)$ but these were all transient. There were no serious adverse events in the Entonox ${ }^{\circledR}$ group.

The final RCT examined the use of Entonox ${ }^{\circledR}$ during ESWL. ${ }^{28}$ Mazdak et al randomised 150 patients undergoing ESWL to receive Entonox ${ }^{\circledR}$, intravenous pethidine or inhalational compressed air. Entonox ${ }^{\circledR}$ and pethidine were both found to significantly reduce procedural pain $(p=0.001)$ as measured using a visual analogue scale. There was no significant difference in pain relief provided by Entonox ${ }^{\circledR}$ and intravenous pethidine.

\section{Discussion}

Entonox ${ }^{\circledR}$ is cheap, easily available, safe, fast acting and rapidly reversible with minor and transient side effects. It is convenient to use and provides patients with an active role in their own pain management. The transient nature of the effects of Entonox ${ }^{\circledR}$ may have a positive impact on financial and workforce resources.

Martin et al showed that Entonox ${ }^{\circledR}$ does not significantly impair complex motor function when used during flexible sigmoidoscopy. ${ }^{29}$ They used an adaptive tracking task that was shown to be the most sensitive test for detecting impairment of driving ability due to drugs. They demonstrated that Entonox ${ }^{\circledR}$ does not impair driving ability and can be used in an outpatient setting. This supports the findings that psychomotor function recovers rapidly in patients who receive Entonox $^{\circledR}$ during a colonoscopy. ${ }^{30}$ However, it is recommended by the manufacturers that patients should not drive for 12 hours after inhaling Entonox ${ }^{\circledR}$. Despite current analgesic options, there is a demand for an agent that would improve patient tolerance of these procedures while allowing it to be performed on an outpatient basis.

\section{Conclusions}

Despite significant evidence in the literature supporting the effectiveness of Entonox ${ }^{\circledR}$ as an analgesic, its use in day case and outpatient urological procedures is still not widespread. This review highlights the potential of Entonox ${ }^{\circledR}$ as an analgesic in such procedures. We believe that Entonox ${ }^{\circledR}$ would significantly enhance patients' experience, is cost effective and poses no significant risk to the majority of patients or staff. We would encourage the wider use of Entonox ${ }^{\circledR}$ as an analgesic in traditionally painful outpatient urological procedures. However, more RCTs of Entonox ${ }^{\circledR}$ versus conventional analgesic options are required to provide further evidence of its efficacy, safety and acceptability to patients.

\section{References}

1. Smith WD. A history of nitrous oxide and oxygen anaesthesia. I: Joseph Priestley to Humphry Davy. Br J Anaesth 1965; 37; 790-798.

2. Breitman F. Psychology does half the work in nitrous oxide analgesia. Dent Surv 1951; 27: 1,081-1,085.

3. Holst JJ. Use of nitrous oxide-oxygen analgesia. Int Dent J 1962; 12: 47-54.

4. Dula DJ. Nitrous Oxide Analgesia. In: Roberts JR, Hedges JR, eds. Clinical Procedures in Emergency Medicine. 2nd edn. Philadelphia: Saunders; 1991. pp508-514.

5. Parbrook GD. The levels of nitrous oxide analgesia. Br J Anaesth 1967 39; 974-982.

6. Parkhouse J, Henrie JR, Duncan GM, Rome HP. Nitrous oxide analgesia in relation to mental performance. J Pharmacol Exp Ther 1960; 128: 44-54.

7. Chapman WP, Arrowood JG, Beecher HK. The analgetic effects of low concentrations of nitrous oxide compared in man with morphine sulphate. J Clin Invest 1943; 22: 871-875.

8. Parbrook GD, Rees GA, Roberston GS. Relief of post-operative pain: comparison of a 25 per cent nitrous-oxide and oxygen mixture with morphine. $\mathrm{Br}$ Med J 1964; 2: 480-482. 
9. Masood J, Shah N, Lane T et al. Nitrous oxide (Entonox) inhalation and tolerance of transrectal ultrasound guided prostate biopsy: a double-blind randomized controlled study. J Urol 2002; 168: 116-120.

10. Stewart RD. No more pain: nitrous oxide. Emerg Med 1986; 18: 49-53.

11. Weimann J. Toxicity of nitrous oxide. Best Pract Res Clin Anaesthesiol 2003; 17: 47-61.

12. Flippo TS, Holder WD. Neurologic degeneration associated with nitrous oxide anesthesia in patients with vitamin B12 deficiency. Arch Surg 1993; 128: $1,391-1,395$.

13. Annequin D, Carbajal R, Chauvin $P$ et al. Fixed $50 \%$ nitrous oxide oxygen mixture for painful procedures: a French survey. Paediatrics 2000; 105: e47.

14. Bryan RA. The success of inhalation sedation for comprehensive dental care within the community dental service. Int J Paediatr Dent 2002; 12: 410-414.

15. Clinical trials of different concentrations of oxygen and nitrous oxide for obstetric analgesia. BMJ 1970; 1: 709-713.

16. Findley I, Chamberlain G. ABC of labour care. Relief of pain. BMJ 1999; 318 927-930.

17. Welchman S, Cochrane S, Minto G, Lewis S. Systemic review: the use of nitrous oxide gas for lower gastrointestinal endoscopy. Aliment Pharmacol Ther 2010; 32: 324-333.

18. Forbes GM, Collins BJ. Nitrous oxide for colonoscopy: a randomized controlled study. Gastrointest Endosc 2000; 51: 271-277.

19. Maslekar S, Gardiner A, Hughes M et al. Randomized clinical trial of Entonox versus midazolam-fentanyl sedation for colonoscopy. Br J Surg 2009; 96: 361-368.

20. Piétrement $\mathrm{C}$, Salomon $\mathrm{R}$, Monceaux $\mathrm{F}$ et al. Analgesia with oxygen-nitrous oxide mixture during percutaneous renal biopsy in children. Arch Pediatr 2001; 8: 145-149.
21. Fosburg MT, Crone RK. Nitrous oxide analgesia for refractory pain in the terminally ill. JAMA 1983; 250: 511-513.

22. Crundwell MC, Cooke PW, Wallace DM. Patients' tolerance of transrecta ultrasound-guided prostatic biopsy: an audit of 104 cases. BJU Int 1999; 83: 792-795.

23. Irani J, Fournier F, Bon D et al. Patient tolerance of transrectal ultrasoundguided biopsy of the prostate. Br J Urol 1997; 79: 608-610.

24. Chaussy $C$, Thuroff S. Pain sensitivity in ESWL patients. Does every stone location need the same analgesia management? J Urol 1996; 159(Suppl): 541.

25. Calleary JG, Masood J, Van-Mallaets R, Barua JM. Nitrous oxide inhalation to improve patient acceptance and reduce procedure related pain of flexible cystoscopy for men younger than 55 years. J Urol 2007; 178:184-188.

26. McIntyre IG, Dixon A, Pantelides ML. Entonox analgesia for prostatic biopsy. Prostate Cancer Prostatic Dis 2003; 6: 235-238.

27. Manikandan R, Srirangam SJ, Brown SC et al. Nitrous oxide vs periprostatic nerve block with $1 \%$ lidocaine during transrectal ultrasound guided biopsy of the prostate: a prospective, randomized, controlled trial. J Urol 2003; 170: $1,881-1,883$.

28. Mazdak H, Abazari P, Ghassami F, Najafipour S. The analgesic effect of inhalational Entonox for extracorporeal shock wave lithotripsy. Urol Res 2007; 35: 331-334.

29. Martin JP, Sexton BF, Saunders BP, Atkin WS. Inhaled patient-administered nitrous oxide/oxygen mixture does not impair driving ability when used as analgesia during screening flexible sigmoidoscopy. Gastrointest Endosc 2000; 51: 701-703.

30. Trojan J, Saunders BP, Woloshynowych M et al. Immediate recovery of psychomotor function after patient-administered nitrous oxide/oxygen inhalation for colonoscopy. Endoscopy 1997; 29: 17-22.

\section{Unethical research}

Recently the Annals received a paper that reported a small randomised comparison of two methods of skin closure after elective surgery. The paper was well received by our reviewers and was thought suitable for publication. However, the review process revealed that the research had been conducted without approval from a research ethics committee (REC). As a result, we were unable to accept the article for publication.

All research involving patients must be approved by such a committee. Failure to obtain REC approval is in clear breach of good clinical practice.

The Annals subscribes to the Committee on Publication Ethics and expects contributors to adhere to normal standards of clinical research practice.

Colin Johnson

Editor-in-Chief

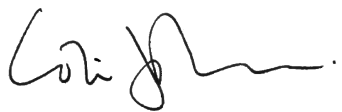

WEG Thomas

Chair, Annals Editorial Board

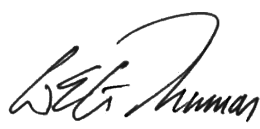

